\title{
Las ideas políticas en el Renacimiento
}

\section{James Hankins (2019) Virtue politics: soulcraft and statecraft in Renaissance Italy, Cambridge, Londres, Belknap Press}

\section{Alejo Perino \\ Universidad de Buenos Aires (Argentina)}

James Hankins es uno de los más importantes especialistas en la historia del pensamiento político de los humanistas del Renacimiento. Su libro sobre el platonismo del Renacimiento es de referencia obligada para los estudios sobre la época, así como sus artículos sobre Leonardo Bruni y el "humanismo cívico". ${ }^{1}$ En este reciente libro reúne el trabajo de muchos años. Consta de veintiún capítulos y tres apéndices. Los dos primeros son traducciones de textos latinos al inglés. El primero de ellos es un pasaje del De vita solitaria de Petrarca. El segundo es un pasaje de la Historia de Bruni y el tercero es una lista de ediciones de Francesco Patrizi.

El libro recorre la historia del humanismo del Renacimiento desde Petrarca hasta el siglo XVI. El concepto que da nombre al libro, es decir virtue politics, hace referencia a una idea recurrente en los textos de los humanistas, aquella que afirma que las formas de gobierno no son tan importantes como la virtud de los gobernantes. En ese sentido, tanto las repúblicas como las monarquías pueden ser formas legítimas si los que gobiernan son virtuosos. Para los humanistas la mejor forma de obtener esa virtud era la lectura de los clásicos, en particular de los studia humanitatis, es decir la gramática, la retórica, la filosofía moral, la poesía y la historia. Esa necesidad de reforma moral estaba asociada también a una nueva manera de ver la historia. Se sabe que la construcción de la idea de Edad Media como edad oscura implicaba una revalorización del pasado glorioso de Roma. De allí que las preguntas más

${ }^{1}$ Ver James Hankins (1991) Plato in the Italian Renaissance, Leiden, Brill; (2000) Renaissance civic humanism: reappraisals and reflections, Cambridge, Cambridge University Press.

Araucaria. Revista Iberoamericana de Filosofí, Política, Humanidades y Relaciones Internacionales, año $23, \mathrm{n}^{\circ} 46$. Primer cuatrimestre de 2021. Pp. 709-714. ISSN 1575-6823 e-ISSN 2340-2199 https://dx.doi.org/10.12795/araucaria.2021.i46.35 
importantes para los humanistas tuvieran como objeto el descubrimiento de las razones históricas de ese éxito y por otro lado las posibilidades de replicarlo. En los primeros dos capítulos Hankins traza el panorama general de ese proyecto.

En los capítulos tres y cuatro, el autor propone una historia de dos conceptos, "república" y "tiranía”. Es sabido que en la Antigua Roma el término res publica no hacía referencia a un modo de gobierno ni a un período histórico particular, con la excepción de Tácito. Sin embargo, algunos humanistas lo utilizaban para designar una forma de gobierno. Es así que en la traducción de la Política de Aristóteles, Bruni, a diferencia de Moerbecke, denomina al buen gobierno de muchos como res publica y no como politia. Hankins rastrea este uso en otros humanistas como Francesco Patrizi y Donato Acciaiuoli. A partir de esta utilización del término surge una disputa con aquellos humanistas, como Pontano y Decembrio que no estaban dispuestos a aceptar que tanto Nápoles como Milán no fueran repúblicas. Hankins da cuenta de esta disputa semántica a través de un comentario a un texto del abuelo de Jerónimo Savonarola, Michele Savonarola, quien en su De vera republica, afirma que solo después de Julio César Roma fue una república porque toda república necesita un príncipe.

En el capítulo sobre la tiranía Hankins expone las diferencias entre un concepto débil de tiranía en Aristóteles y Jenofonte y la concepción romana transmitida por Cicerón, en la cual la tiranía es una violación de la ius civile, que a su vez es la expresión de la ley natural. La cuestión de la tiranía es muy debatida durante el Renacimiento. En primer lugar, por Bartolo de Sassoferrato y Baldo degli Ubaldi. En su De tyranno, Bartolo afirma que existen tiranos por defecto de su título, es decir que han accedido al poder de forma ilegal, pero también hay tiranos que imponen una ley a través del miedo, y otros que han accedido legalmente pero ejercen su poder tiránicamente. Su discípulo, Baldo degli Ubaldi, consideraba que la solución legal al problema de la tiranía era la autonomía de la ley. Pero sin duda, el suceso clave para comprender la importancia de este concepto es el debate en torno a la figura de César de principios del Quattrocento. Coluccio Salutati en su De tyranno defiende a César y a Dante por haber condenado a sus asesinos. La siguiente generación de humanistas, con Leonardo Bruni y Poggio Bracciolini a la cabeza, no acuerda con esa postura y sigue a Cicerón, su principal influencia. Guarino de Verona, uno de los más importantes maestros humanistas, le responde a Poggio en defensa de César. Sin embargo, las tesis de Poggio son aún más radicales: en De infelicitate principum parece sostener la idea de que toda dominación política es corrupta y que la virtud solo puede florecer lejos del poder.

El siguiente punto a desarrollar es la lectura que realizan los humanistas de los tiranos de la Antigüedad a partir de tres fuentes: la República de Platón, traducida por Decembrio, las Cartas atribuidas a Platón, traducidas por Bruni, y sobre todo, Heródoto, traducido por Lorenzo Valla. A diferencia de los filósofos 
del siglo IV a. C. Heródoto no diferencia entre buenos reyes y tiranos. Para él, toda forma de autocracia es ilegítima. El conflicto aparece con el Hierón de Jenofonte, traducido por Bruni en 1403, en donde puede apreciarse una postura más benigna sobre la tiranía y con la literatura filotiránica de la segunda sofística, sobre todo de las Cartas de Falaris, una colección escrita alrededor de 190 d. C. probablemente bajo la influencia de Luciano. Las cartas fueron traducidas por Francesco Griffolini de Arezzo. En ellas se muestra una versión del tirano de Falaris completamente distinta a la que la tradición le atribuye. A partir de estos textos se sostiene la idea de que la reputación del tirano puede ser una cuestión de percepción.

En los siguientes capítulos el autor analiza la obra de distintos humanistas. Comentaremos brevemente aquellos que resultan menos conocidos para el lector, dejando un tanto al margen a los grandes autores como Petrarca, Bruni o Maquiavelo.

Uno de los historiadores más importantes del siglo XV, Flavio Biondo, es conocido por haber sido el primero en periodizar la Edad Media desde la caída del Imperio hasta el 1400. Para Biondo la respublica indica un período en la historia de Roma. Siguiendo a Floro y otros historiadores imperiales, Biondo divide la Historia romana en tres períodos (sub regibus, sub consulibus, sub imperatoribus). Otros términos que utiliza para denominar el período consular es libera civitas y stans et integra republica. Biondo destaca tres factores que explican el éxito de Roma. El primero es el religioso. El segundo es la habilidad para admitir extranjeros como ciudadanos e incluso en las magistraturas. Esas simpatías cosmopolitas ilustran la preferencia romana por la virtud y no por el nacimiento, que por otro lado es una cuestión que aparece en casi todos los humanistas. La tercera es, por supuesto, la virtud de sus líderes.

Ciríaco de Ancona (1391-1452) es, a juicio de Hankins, el único autor del Renacimiento que utiliza el término democratia en latín en un sentido positivo. Su fuente parece ser el libro VI de la Historia de Polibio, que se creía descubierto en el siglo XVI. La influencia de la teoría de la anacyclosis es notoria en un texto de 1490/91, el De comparatione rei publicae et regni, de Aurelio Lippo Brandolini, texto editado por el propio Hankins. ${ }^{2}$

George de Trebizonda fue un importante humanista nacido y formado en el mundo helénico y emigrado a Roma. Es conocido por haber traducido las Leyes de Platón. Hankins trabaja la idea de cosmopolitismo en su Comparatio philosophorum Aristotelis et Platonis. Sus críticas a la comunidad de Magnesia ideada por Platón están relacionadas justamente con la valoración positiva de la ciudad cosmopolita. Por eso afirma que Rómulo fue mucho más sabio que Platón y su actitud inclusiva hizo a Roma más grande que cualquier otra civilización.

\footnotetext{
${ }^{2}$ Aurelio Lippo Brandolini (2009) Republics and Kingdoms Compared, James Hankins (ed.) The I Tatti Renaissance Library; 40. Cambridge, Mass.: Harvard University Press
}

Araucaria. Revista Iberoamericana de Filosofia, Política, Humanidades y Relaciones Internacionales, año $23, \mathrm{n}^{\circ} 46$. Primer cuatrimestre de 2021. Pp. 709-714. ISSN 1575-6823 e-ISSN 2340-2199 https://dx.doi.org/10.12795/araucaria.2021.i46.35 
Aún más extraño es el elogio que Trebizonda hace del imperio otomano, el gran rival del occidente cristiano en la época, por las mismas razones que la Roma clásica, su inclusión de los extranjeros. El único defecto que tenían los turcos era el religioso. Por eso, Trebizonda participó en una comisión enviada en 1466 a Constantinopla para convertir al sultán Mehmed II al cristianismo. Hankins considera que una de las fuentes del cosmopolitismo de Trebizonda es un discurso de Elio Arístides, el Encomium Romae. Según este discurso, los griegos fallaron en construir un imperio porque no supieron cómo gobernar las ciudades que anexaban, las explotaban y tiranizaban. Los romanos, en cambio, habían comprendido que la mejor manera de gobernar esas ciudades era dándole la ciudadanía a los mejores hombres.

Francesco Filelfo, otro intelectual de origen griego, le dedica en 1430 al cardenal Niccolò Albergati tres traducciones de Jenofonte y Plutarco sobre los espartanos. Filelfo ponderaba la capacidad de los espartanos para prevenir la influencia de los ciudadanos ricos en el Estado, lo cual es claramente una crítica a Cosme de Médici, su principal enemigo. El modelo espartano era elogiado por el estricto control y el privilegio del bien común sobre las libertades individuales.

Francesco Patrizi, formado por Filelfo en Siena, es, como su maestro, uno de los humanistas itinerantes que sirvieron a varios patrones en la península. Es exiliado de Siena por participar en una conjura. En Verona, conoce a Battista Guarino, el hijo del maestro humanista. Su suerte cambia cuando su patrón, Eneas Silvio Piccolomini, se convierte en el papa Pío II. En poco tiempo lo nombra gobernador de Foligno, de donde es expulsado luego de un levantamiento. Finalmente, encuentra su lugar en Nápoles, bajo la protección de Alfonso de Aragón. Completó su obra De regno et regis institutione entre 1483 y 1484. Este texto suele encontrarse agrupado con otros tratados de la época, como el De principe de Pontano, los De optimo cive y De principe de Bartolomeo Platina, los De eruditione principum y De principis officio de Giovanni Garzoni y una larga lista de textos escritos en la segunda mitad del siglo $\mathrm{XV}$.

Uno de los puntos más interesantes del De regno es la argumentación a favor de la monarquía tomada de Isócrates. Mientras que las repúblicas no fomentan el bien común porque cada ciudadano se preocupa por su propio bienestar, los reyes suelen rodearse de las personas más capaces que resultan más provechosas para el Estado. Por otro lado, las monarquías son más estables y una solución contra la sedición y el faccionalismo. La superioridad de la monarquía también se sostiene en argumentos teológicos, ya que históricamente tiene un origen divino. 
El uso de fuentes griegas para argumentar a favor de la monarquía es un aspecto interesante del siglo XV. En 1442 el cardenal Bessarion traduce los Memorabilia de Jenofonte, con el título De dictis et factis Socratis. En ese texto se encuentra la primera aparición conocida de la distinción entre monarquía ( $\beta \alpha \sigma \imath \lambda \varepsilon i ́ \alpha)$ y tiranía ( $\tau$ p $\alpha v v i ́ \varsigma)$. La Ciropedia, otro de los textos importantes de Jenofonte, también fue popular durante el Renacimiento, en las traducciones de Poggio Bracciolini y Francesco Filelfo. Para este último, el ejemplo de la Ciropedia se utiliza para demostrar la superioridad de la monarquía.

Otras fuentes griegas sobre la monarquía eran los textos de Isócrates dedicados al rey Nicocles de Chipre y Dión de Prusa. Patrizi cita a ambos autores en De regno. El Ad Nicoclem fue importante desde Guarino de Verona hasta el propio Erasmo.

Los últimos capítulos están dedicados a Maquiavelo. Uno de los aspectos más interesantes que señala Hankins es la ruptura que Maquiavelo realiza respecto de la tradición humanista. Su cultura era más vernácula que latina, y su interés en los autores de la Antigüedad se limitaba a Tito Livio. Hay otros aspectos en los que Maquiavelo se diferencia de la tradición humanista y Hankins señala un pasaje del prefacio del libro V de la Historia florentina en el que Maquiavelo critica irónicamente el otium cum dignitate ciceroniano y habla del estudio de la filosofía como raíz de la corrupción moral. Es por eso que la imitación de los antiguos debe tener un matiz fuertemente práctico. Los romanos deben ser imitados porque tuvieron éxito, basado en la militarización de toda la sociedad.

El capítulo veinte, "Two cures for hyperpartisanship: Bruni versus Machiavelli" establece una comparación entre las historias de la ciudad de Florencia que ambos autores escribieron. Llaman la atención las diferencias sobre la figura de Walter de Brienne, el noble francés que gobernó Florencia entre 1342 y 1343. Para Bruni, la nobleza conspiró para promoverlo. Maquiavelo considera que también participó el popolo grasso. Otro punto que los diferencia reside en las causas de la caída del tirano. Bruni apunta a sus propios errores y falta de virtud, mientras que para Maquiavelo Walter no tenía el poder suficiente ni el apoyo externo para sostener en el tiempo un gobierno tiránico.

La restauración de las instituciones luego de la expulsión del tirano no fue sencilla. Para Bruni, fue un error haber restaurado los derechos políticos a los nobles. Maquiavelo recurre a la historia de Roma para explicar su postura. Conflictos entre las clases existieron siempre y no pueden eliminarse, pero sí establecer un equilibrio a través de la ley como se logró durante un tiempo en Roma, y no a través del faccionalismo y el exilio como sucedió siempre en Florencia. Para Hankins, la propuesta de Maquiavelo es más realista y practicable a los ojos de un observador moderno. En el fondo, Maquiavelo, a diferencia de los humanistas, no cree en la virtud de las elites. 
El capítulo veintiuno "Conclusion: Ex Oriente Lux" trabaja sobre la figura de Matteo Ricci, misionero jesuita que a fines del siglo XVI conoció al pensador Zhang Huang y elogió la cultura china como modelo para Europa. Hankins establece un paralelismo entre el humanismo y el confucionismo, en tanto que ambos plantean una renovación política y moral en base al estudio de los textos clásicos. La diferencia es que el primero triunfó mientras que el segundo fracasó.

Las páginas finales del libro intentan encontrar alguna enseñanza que haya dejado la tradición humanista. Uno de los puntos que rescata es la idea de que la autoridad política no se sostiene sin autoridad moral, y que la autoridad moral se consigue solo cuando el gobernante conoce a fondo el pueblo que dirige.

El libro tiene muchos aspectos interesantes. En primer lugar, colabora en desmitificar la idea de una tradición republicana defendida por los humanistas durante el Renacimiento. Si hay una coherencia política en el humanismo se relaciona con el interés por mejorar a las elites a través de los ejemplos clásicos. Es por eso que la historia de la recepción de los clásicos durante el siglo XV es muy importante. Hankins demuestra que fueron decisivos no solo Platón y Aristóteles, sino también Jenofonte, Isócrates, Plutarco, Heródoto y Polibio. El acceso a nuevas fuentes implicó también la revalorización de otros modelos además de Roma y Atenas, como el elogio de Bruni a los etruscos o el de Filelfo a los espartanos. En segundo lugar, es clara la ruptura de Maquiavelo respecto a la creencia de que la elocuencia y los ejemplos clásicos podían ejercer alguna influencia decisiva en el comportamiento de los poderosos. Por supuesto, durante el siglo XVI esa creencia continuó ejerciendo su poder. Basta considerar vida y obra de Erasmo para comprobarlo. El fuerte entusiasmo por el mundo clásico que duró aproximadamente dos siglos coincidió no casualmente con una infrecuente confianza en la palabra y en su capacidad de persuasión. Por eso el diálogo filosófico fue uno de los géneros más utilizados por los humanistas. En esos diálogos era común encontrar posiciones contradictorias sin que existiera una síntesis o una conclusión decisiva. Fue para algunos la vía ideal para transmitir contenido heterodoxo sin asumir la responsabilidad de la autoría. Así también sucedió con las ideas políticas y Hankins acierta en analizar no solamente los tratados políticos o los espejos de príncipes, sino también esos diálogos y obras más vinculadas con lo que hoy llamamos literatura, como las biografías o las cartas. En ese sentido, una posible conclusión sobre el pensamiento político en el Renacimiento debe plantearse no como la postulación de una u otra doctrina, sino como la convivencia dialógica de modelos muy diversos. 


\section{Referencias bibliográficas}

James Hankins. (1991). Plato in the Italian Renaissance. Leiden: Brill.

James Hankins. (2000). Renaissance civic humanism: reappraisals and reflections. Cambridge: Cambridge University Press.

Aurelio Lippo Brandolini. (2009). "Republics and Kingdoms Compared". En James Hankins (ed.). The I Tatti Renaissance Library. Cambridge: Harvard University Press. 
